\title{
Evaluasi Pemanfaatan Teknologi Informasi Di Desa Tarinsing Menggunakan Metode Cobit 5.0
}

\author{
Hewu Teguh ${ }^{1}$ Kristoko Dwi Hartomo² \\ 1,2,3 Jurusan Sistem Informasi, Fakultas Teknologi Informasi Universitas Kristen Satya Wacana \\ Jl.Diponegoro No.52-60, Salatiga, Kec.Sidorejo, Jawa Tengah Telp/Fax. (+62) 8112772122 \\ email: 'hewuteguh005@gmail.com, ${ }^{2 k r i s t o k o @ u k s w . e d u ~}$
}

\begin{abstract}
Abstrak
Teknologi Informasi mempunyai peran penting bagi suatu lembaga tak terkecuali bagi Kantor Pemerintahan Desa Tarinsing, Kabupaten Barito Timur, Kecamatan Paku, Provinsi Kalimantan Tengah yang wajib menjalankan program pemerintah untuk bisa mengikuti perkembangan teknologi dan meningkatkan kemampuan dalam mengelola data kependudukan agar bisa memberikan pelayanan yang akurat dan maksimal kepada masyarakat desa sebagaimana yang ditulis dalam amanat Inpres No.3 Tahun 2003. Untuk bisa memberikan kegunaan Teknologi Informasi secara akurat dan maksimal serta selaras dengan tujuan organisasi diperlukan dukungan tata kelola TI yang maksimal. Namun, dalam Kantor Pemerintahan masih belum ada proses yang memastikan keuntungan dalam setiap kegiatan yang dijalankan dalam pengadaaan optimasi risiko serta pencapaian yang sesuai dengan tujuan organisasi, maka dari itu diperlukan suatu evaluasi tata kelola guna untuk mengetahui sejauh mana Tata Kelola SI/TI pada Kantor Pemerintahan ini. Dalam evaluasi Tata Kelola ini, framework yang digunakan adalah framework COBIT 5. Dimana domain yang digunakan berfokus pada EDM (Evaluate, Direct, and Monitor) Berdasarkan hasil yang diperoleh dari perhitungan tingkat kapabilitas saat ini pengadaan SI/TI pada Kantor Pemerintahana Desa Tarinsing masih berada pada tingkat 1 yang artinya proses dijalankan dengan capaian nilai sebesar 1,5. Kondisi tersebut memberikan gambaran bahwasannya implementasi SI/TI pada Kantor Pemerintahan Desa Tarinsing telah dijalankan dan mencapai tujuannya namun masih memerlukan pengadaan optimasi risiko agar dicapai output yang sesuai dengan tujuan organisasi.
\end{abstract}

Kata kunci - Evaluasi Tata Kelola , Framework Cobit 5.0, EDM (Evaluasi, Direct, Monitor)

\section{PENDAHULUAN}

Perkembangan Teknologi Informasi yang semakin pesat merupakan cara bagi sebuah organisasi baik profit dan non-profit, swasta serta pemerintahan untuk meningkatkan kualitas informasi, menghemat biaya, meningkatkan daya saing serta peningkatan produktivitas aset yang dimiliki oleh suatu instansi. Dilihat dari penting nya fungsi dan peranan teknologi informasi, maka diperlukan suatu tata kelola SI/TI yang mampu mengevaluasi teknologi informasi secara mendalam di suatu lembaga maupun instansi tertentu agar bisa mendapatkan kegunaan SI/TI yang selaras dengan tujuan suatu lembaga atau instansi, oleh karena itu diperlukan sebuah pengelolaan SI/TI yang baik dan benar, sehingga keberadaan SI/TI dapat dirasakan dan mendukung pencapaian visi dan misi suatu lembaga atau instansi terutama bagi pemerintahan, baik pada pemerintahan pusat maupun pemerintahan daerah seperti pemerintahan kota hingga sampai di pemerintahan desa. Desa 
merupakan pembagian wilayah administratif di Indonesia yang berada dibawah pimpinan kecamatan dan dipimpin oleh Kepala Desa yang memiliki kewajiban dalam meningkatkan koordinasi penyelanggaraan pemerintahan, dan pelayanan publik.[1].

Desa Tarinsing adalah salah satu desa di Kecamatan Paku, Kabupaten Barito Timur, Provinsi Kalimantan Tengah yang memiliki kewajiban untuk memberikan pelayanan kepada masyarakat desa. Dalam perjalanan untuk mencapai tujuannya, Desa Tarinsing telah mengitegrasikan SI/TI pada setiap proses kegiatan, baik dalam proses kegiatan internal maupun external untuk melayani masyarakat. Penerapan Teknologi Informasi pada Kantor Pemerintahan Desa Tarinsing dapat dilihat dengan adanya penerapan aplikasi pendukung seperti aplikasi SISKEUDES untuk transparasi pengelolaan keungan, aplikasi Sistem Pengelolaan Aset Desa (SIPADES), Pelatihan Aplikasi Desa Covid-19 (eDMC-19) adalah upaya untuk melawan Covid-19 yang memberikan informasi secara realtime seputar Covid-19, serta software Microsoft Office untuk mendukung kinerja di bagian pelayanan masyarakat dalam mengurus surat-menyurat.

Pada setiap proses yang dijalankan tidak selamanya TI memberikan keberhasilan dan dapat menyelaraskan tujuan organisasi, tentu dalam setiap pengelolaan aset SI/TI selalu ada potensi resiko yang besar, disebabkan oleh nilai investasi yang menyertainya juga besar. Untuk mengatasi hal tersebut organisasi memerlukan suatu evaluasi yang dapat membantu merapikan tata kelola TI yang sesuai dengan standar tata kelola SI/TI. Tata kelola teknologi informasi adalah sebuah pengelolaan yang memastikan aset infrastruktur sumber daya SI/TI pada suatu lembaga maupun instansi dapat mendukung pencapaian strategi dan tujuan suatu lembaga maupun instansi yang menerapkan penggunaan teknologi informasi[2].

Tata kelola Teknologi Informasi adalah framework yang mampu mengukur aset SI/TI pada suatu organisasi atau instansi serta mampu memperoleh pencapaian strategi yang seusai dengan tujuan organisasi atau instansi[3]. Evaluasi tata kelola SI/TI juga diperlukan untuk menjalankan dan memastikan kesesuaian dari organisasi teknologi informasi dengan tujuan organisasi agar penggunaan SI/TI di organisasi dapat secara optimal membuat organisasi atau sebuah instansi dapat mencapai target dari tujuannya [4].

COBIT (Control Objective For Information and Related Technology) merupakan salah satu kerangka kerja tata kelola teknologi informasi yang sesusai dengan standar internasional dalam mengevaluasi tata kelola SI/TI. Dibandingkan dengan kerangka kerja yang lain, COBIT 5 memiliki cakupan yang lebih lengkap dan detail karena COBIT 5 sudah memiliki materi yang terdapat pada kerangka kerja lain seperti ISO 38500, ISO 31000 yang masuk dalam area tata kelola domain EDM (Evaluate, Direct, Monitor), ISO 27000, ITIL V3, dan PRINCE2 yang maasuk dalam area tata kelola domain APO (Align, Plan, Organise)[2][5].

\section{METODE PENELITIAN}

Kerangka penelitian sebagaimana yang ditunjukkan pada Gambar 1. yang mendesripsikan proses penyelesaian masalah pada penelitian ini yang mengacu pada kerangka kerja COBIT 5, Framwork tersebut didapat dari ISACA.[6]. 
Tahap Pertama, Perencanaan Penelitian
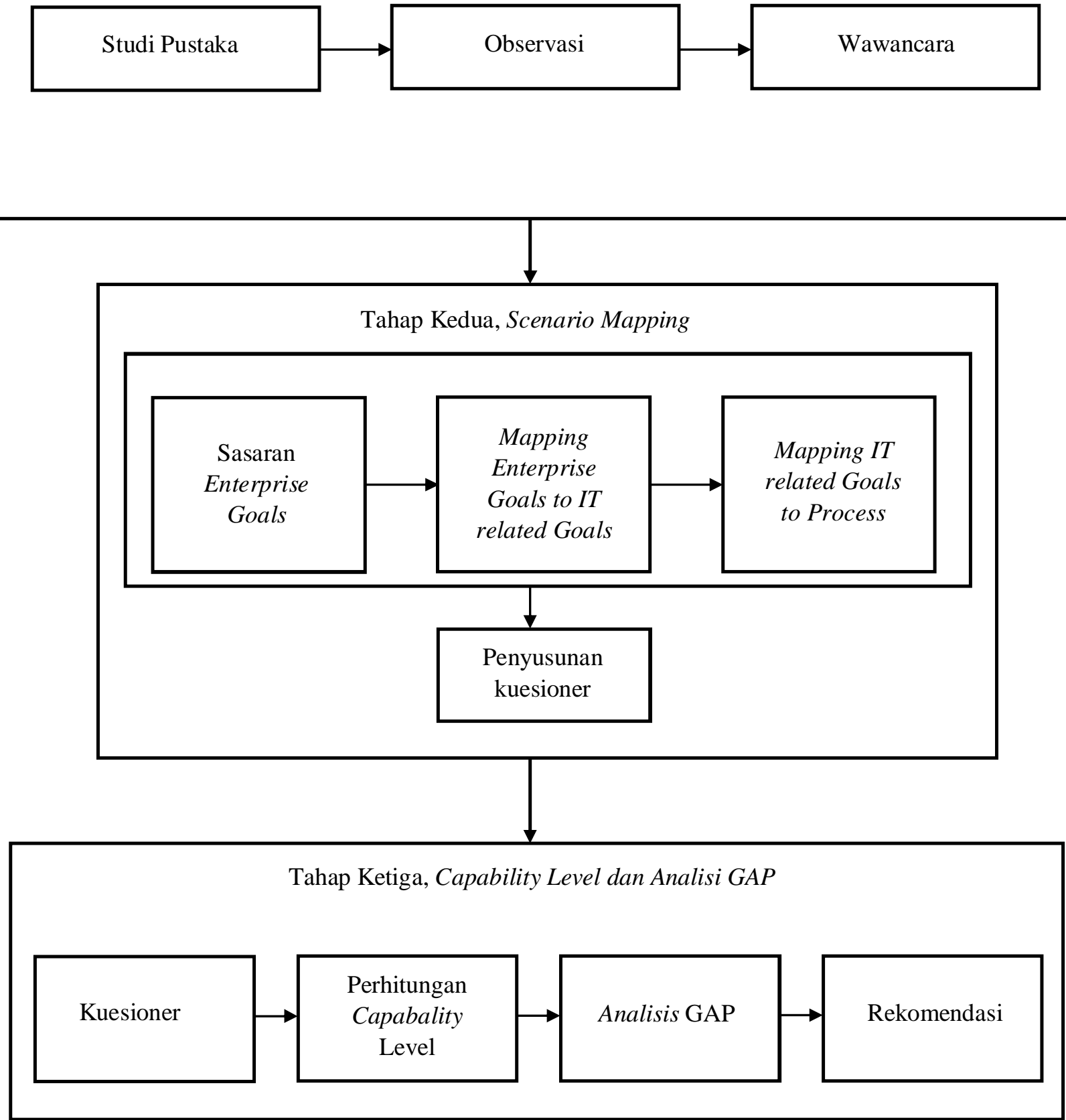

Gambar 1. Kerangka Penelitian

Teguh, et., al [Evaluasi Pemanfaatan Teknologi Informasi Di Desa Tarinsing Menggunakan Metode Cobit 5.0] 
Berikut adalah penjelasan pada Gambar 1. berdasarkan masing-masing proses dari tahapan kerangka penelitian:

\section{A. Perencanaan Penelitian}

Pada tahap awal penelitian ini, peneliti menyusun rencana awal penelitian untuk menemukan domain yang sesuai dengan ruang lingkup kebutuhan penelitian pada COBIT 5 dengan cara melakukan studi pustaka melalui beberapa referensi dengan yang berkaitan objek penelitian, observasi pada objek penelitian serta wawancara dengan narasumber dari pihak studi kasus.

B. Scenario Mapping

Tahap yang kedua bertujuan untuk menggambarkan pemetaan sasaran strategis pada Desa Tarinsing yang sesuai dengan tujuan COBIT 5 untuk menemukan sasaran strategis yang sesuai. Tujuan dari tahap ini adalah untuk mendapatkan proses-proses yang berguna bagi peneliti untuk nantinya dapat digunakan untuk referensi untuk menentukan perancangan kuesioner evaluasi.

\section{Capability dan Analisis GAP}

Pada tahap terakhir, dengan cara menyusun serta menjabarkan temuan-temuan dari kuesioner evaluasi yang digunakan peneliti sebagai acuan, maka peneliti dapat melakukan perhitungan untuk mengukur tingkat kapabilitas dan analisis kesenjangan untuk setiap domain EDM01 (Ensure Governance Framework setting and maintenance), EDM02 (Ensure Benefits Delivery), EDM03 (Ensure Risk Optimisation), dan EDM05 (Ensure Stakeholder Transparency).

Process Assessment Model (PAM) merupakan model pengukuran proses pada kerangka kerja COBIT 5. PAM dalam COBIT 5 ditentukan dengan teknik pengukuran berskala tingkat (scale rating) yang berguna untuk menilai dimensi proses yang terdiri dari 5 dimensi proses EDM, APO, BAI, DSS dan MEA. Pada International Organization for Standardization (ISO)/International Electrotechnical Commission (IEC) 15504 Terdapat 6 (enam) tingkatan kapabilitas yang didapatkan pada tahap sebelumnya, yakni :

1) Proses tidak lengkap. proses ini gagal mencapai tujuannya karena pada proses ini tidak dapat mengaplikasikan proses.

2) Proses dijalankan. proses ini mampu untuk mengaplikasikan prosses dengan begitu dalam proses ini dapat mencapai tujuannya.

3) Proses teratur. proses ini dapat dijalankan dan mengaplikasikan proses menggunakan cara yang lebih teratur dan juga terstruktur, serta mampu memonitoring proses yang dihasilkan dengan lebih baik.

4) Proses tetap. Pada proses ini SI/TI dapat dijalankan dan sudah menggunakan proses tertentu yang sudah diatur dan dapat mencapai tujuan yang diharapkan.

5) Proses yang dapat diprediksi. Pada tahap ini sudah menerapkan proses dengan batasan yang sudah ditentukan sebelumnya, agar mendapatkan hasil yang sesuai.

6) Proses optimasi. Pada tahapan ini menjalankan proses yang menekan peningkatan proses secara terus menerus dan berkesinambungan sehingga tujuan dari lembaga maupun instansi pada saat ini serta di masa yang akan datang sesuai dengan yang diharapkan.

Selajutnya, pada proses penilaian tingkat kapabilitas dijalankan, pada tahap yang berikutnya peneliti akan melakukan proses analisis kesenjangan. Analisis kesenjangan ini dapat digunakan untuk menghitung serta mengukur tingkat kapabilitas yang terdapat pada objek yang didapatkan dari hasil evaluasi pada tingkat kapabilitas yang sesuai dengan kerangka kerja COBIT 5. Analisis kesenjangan dilakukan dalam masing-masing tahapan domain yang digunakan.

\subsection{Pengacuan Pustaka}

COBIT 5 merupakan kerangka kerja organisasi untuk menciptakan hasil yang maksimal dari tata kelola teknologi informasi dengan menjaga kesetaraan antara menyadari manfaat aset SI/TI dan

Teguh, et., al [Evaluasi Pemanfaatan Teknologi Informasi Di Desa Tarinsing Menggunakan Metode Cobit 5.0] 
mengoptimalkan tingkat risiko serta penggunaan sumber daya SI/TI. Selain itu juga prinsip dan kemampuan COBIT 5 dapat diimplementasikan pada perusahaan atau organisasi berskala besar maupun kecil, baik yang swasta, non-profit, juga pada sektor pelayanan publik.[7].

Pada penelitian sebelumnya yang berkaitan dengan evaluasi tata kelola TI menggunakan kerangka kerja COBIT 5. Penelitian yang dilakukan oleh Abdul [8], berdasarkan evaluasi pada Pusat Data dan Teknologi Informasi (ESDM) memperoleh hasil pada domain EDM, dengan target capaian rata-rata 2, dapat disimpulkan bahwa sistem pengelolaan TI masih lemah. Akan tetapi pada domain APO (Align, Plan, and Organise) dengan nilai rata-rata 4, menunjukkan bahwa sistem manajemen TI sudah bagus namun tetap harus dikembangkan. Perolehan nilai yang kurang bagus terdapat pada APO subdomain APO13 (Security Management) yang hanya mampu mendapatkan nilai rata-rata 2.38 yang artinya masih adanya kelemahan dalam penanganan kemanan dalam pengelolaan TI. Kondisi tersebut akan mengganggu distribusi data dan kinerja pengguna. Dan hasil penelitian evaluasi pada domain BAI (Build, Acquire and Implementasi) dengan target capaian 3 menunjukan hampir seluruhnya memenuhi syarat. Namun masih terdapat kerenggangan pada bagian perubahan sistem baik dari segi software dan hadware dikarenakan tidak adanya pendokumentasian memadai.

Kemudian penelitian yang dilakukan oleh Selvia, dengan menggunakan framework COBIT 5 dan domain EDM01, EDM 04, APO 01, APO 04, APO 07, BAI 02, BAI08, DSS01 dan MEA01 adalah 2.24 yaitu Managed Process. untuk mempertimbangkan tingkat kematangan tata kelola SI/TI pada aspek manajemen SDM sebagai salah satu cara mengetahui sistem dari sudut pandang teknologi dan untuk menilai pencapaian pada manajemen pengelolaan SDM.

Hal yang sama dilakukan oleh Hengki[9], dalam penelitiannya menggunakan kerangka kerja COBIT 5 dan menggunakan domain Evaluate, Direct and Organise (EDM), Align, Plan And Organise (APO), Build, Acquire and Implement (BAI), Deliver, Service and Support (DSS), Monitor, Evaluate and Assess (MEA) untuk mengukur tingkat kematangan implementasi TI Akademik pada STIMIK Pelita Nusantara Medan, Hal tersebut dikarenakan COBIT 5 lebih fokus kepada proses-proses yang hanya dinilai sesuai dengan hasil pemetaan proses yang telah dilaksanakan.

Evaluasi tata kelola pemanfaatan Teknologi Informasi di Kantor Pemerintahan Desa Tarinsing bertujuan untuk memperkirakan tingkat kematangan dan mengukur sejauh mana tata kelola TI di Kantor Pemerintahan Desa Tarinsing. Domain Evaluate, Direct and Monitoring (EDM) menjadi sasaran utama dalam penelitian ini karena proses domain EDM secara keseluruhan dapat mendeskripsikan proses tata kelola.

\section{HASIL DAN PEMBAHASAN}

A. Menentukan Domain dan Kontrol Proses

1) Target organisasi. Pada tahap menentukan target organisasi yang mengarah pada tujuan COBIT 5, mencakup 17 target organisasi secara umum dapat dikelompokan sesuai dengan dimensi keluaran yang dihasilkan[6]. Untuk mengalokasikan sasaran dan tujuan organisasi dijalankan menggunakan cara menyelaraskan COBIT tujuan organisasi dengan tujuan Desa Tarinsing. Hasil dari tahapan ini adalah pemetaan tujuan pada pemerintahan Kantor Pemerintahan Desa Tarinsing. Hasil dari pemetaan tersebut dapat dilihat pada Gambar 2.

Teguh, et., al [Evaluasi Pemanfaatan Teknologi Informasi Di Desa Tarinsing Menggunakan Metode Cobit 5.0] 


\begin{tabular}{|c|c|c|c|c|c|c|c|c|c|c|c|c|c|c|c|c|}
\hline \multicolumn{17}{|c|}{ Enterprise Goal } \\
\hline 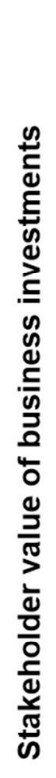 & 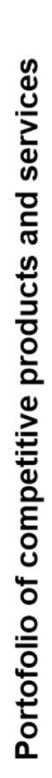 & 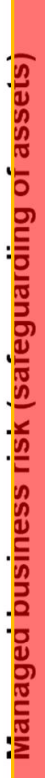 & 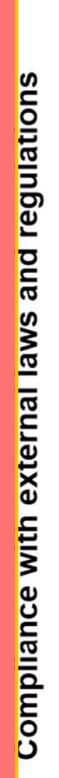 & 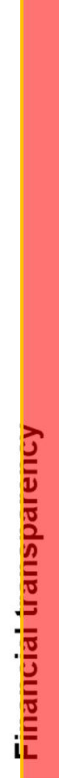 & 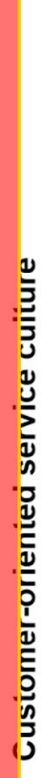 & 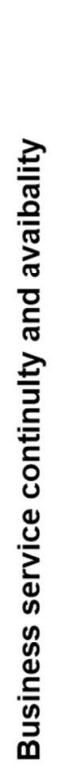 & 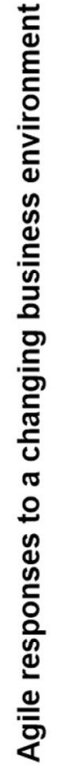 & 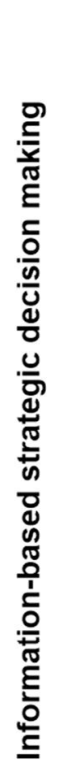 & 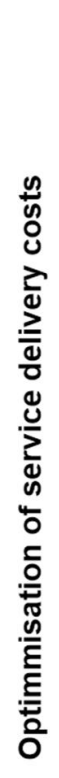 & 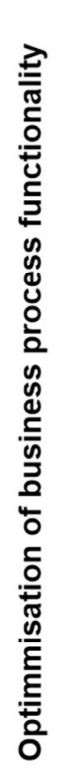 & 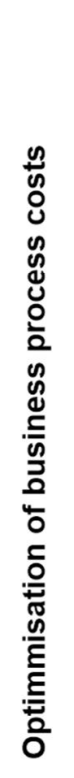 & 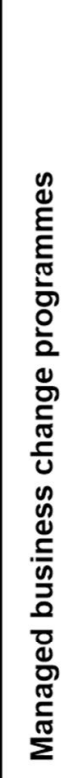 & 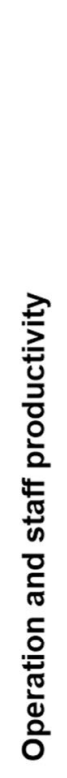 & 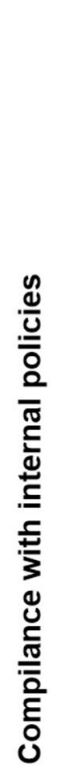 & 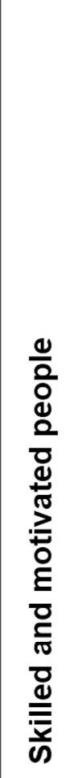 & 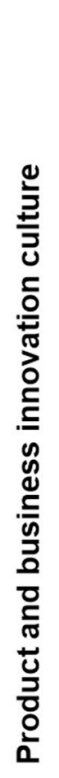 \\
\hline 1 & 2 & 3 & 4 & 5 & 6 & 7 & 8 & 9 & 10 & 11 & 12 & 13 & 14 & 15 & 16 & 17 \\
\hline \multicolumn{5}{|c|}{ Financial } & \multicolumn{5}{|c|}{ Customer } & \multicolumn{5}{|c|}{ Internal } & \multicolumn{2}{|c|}{$\begin{array}{l}\text { Learning } \\
\text { and } \\
\text { Growth }\end{array}$} \\
\hline
\end{tabular}

Gambar 2. Hasil Pemetaan Sasaran Tujuan Kantor Pemerintahan Desa Tarinsing

2) Pemetaan Target Organisasi dalam sasaran SI/TI. Dalam pemetaan ini tujuan yang menyangkut sasaran SI/TI dengan COBIT 5 tergambarkan dengan jelas bagaimana setiap prosesnya [6].

Pada Gambar 3 dibawah ini. Menggambarkan hasil dari pemetaan terkait sasaran SI/TI dari tujuan organisasi yang dimana P merupakan Primer, yang menunjukkan terdapat relasi penting yang terdapat kaitanya dengan SI/TI sebagai dukungan utama dalam tujuan organisasi. Kemudian S merupakan Sekunder, yang menunjukkan adanya relasi yang kuat namun masih kurang diprioritaskan karena tujuan yang berhubungan dengan sasaran SI/TI sebagai dukungan sekunder bagi tujuan organisasi. Pemetaan relasi tersebut, baik $\mathrm{P}$ maupun $\mathrm{S}$ terarah kedalam proses yang terdapat di COBIT 5[6]. 


\begin{tabular}{|c|c|c|c|c|c|c|c|c|c|c|c|c|c|c|c|c|c|c|c|}
\hline & & & \multicolumn{17}{|c|}{ Enterprise Goal } \\
\hline & & & 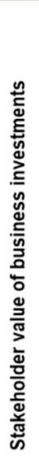 & 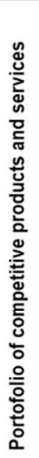 & 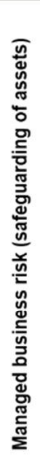 & 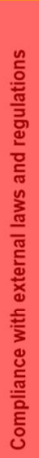 & 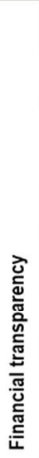 & 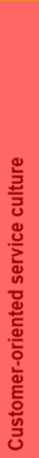 & 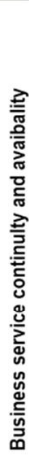 & 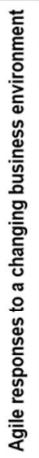 & 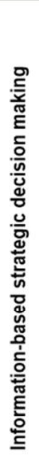 & 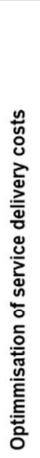 & 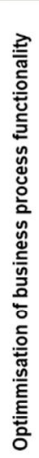 & 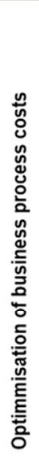 & 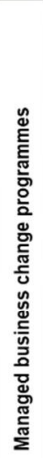 & 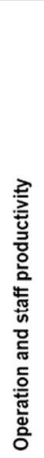 & 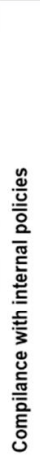 & 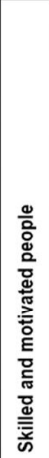 & 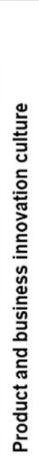 \\
\hline & & & 1 & 2 & 3 & 4 & 5 & 6 & 7 & 8 & 9 & 10 & 11 & 12 & 13 & 14 & 15 & 16 & 17 \\
\hline & & IT-related Goal & \multicolumn{5}{|c|}{ Financial } & \multicolumn{5}{|c|}{ Customer } & \multicolumn{5}{|c|}{ Internal } & \multicolumn{2}{|c|}{$\begin{array}{l}\text { Learning } \\
\text { and } \\
\text { Growth }\end{array}$} \\
\hline \multirow{6}{*}{ 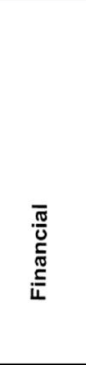 } & 1 & Alignment of $I T$ and business strategy & $P$ & $\mathbf{P}$ & S & & & $\mathbf{P}$ & S & P & $\mathbf{P}$ & S & P & S & P & & & S & S \\
\hline & 2 & $\begin{array}{l}\text { IT complance and suport for business } \\
\text { complance with external laws and regulations }\end{array}$ & & & S & $\mathbf{P}$ & & & & & & & & & & & $\mathbf{P}$ & & \\
\hline & 3 & $\begin{array}{l}\text { Commitment of executive management } \\
\text { for making IT }\end{array}$ & $\mathbf{P}$ & S & S & & & & & $\mathbf{S}$ & $\mathbf{S}$ & & $\mathbf{S}$ & & $\mathbf{P}$ & & & $\mathbf{S}$ & $\mathbf{S}$ \\
\hline & 4 & Managed IT-related business risk & & & $P$ & S & & & $\mathbf{P}$ & S & & $\mathbf{P}$ & & & S & & $\mathbf{S}$ & $\mathbf{S}$ & \\
\hline & 5 & $\begin{array}{l}\text { Realised benefit from IT-enabled investments } \\
\text { and services portofolio }\end{array}$ & $\mathbf{P}$ & $\mathbf{P}$ & & & & $\mathbf{S}$ & & $\mathbf{S}$ & & $\mathbf{S}$ & $\mathbf{S}$ & $\mathbf{P}$ & & $\mathbf{S}$ & & & S \\
\hline & 6 & Transparency of IT costs, benefits and risk & S & & $S$ & & P & & & & S & $P$ & & $P$ & & & & & \\
\hline 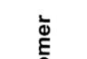 & 7 & $\begin{array}{l}\text { Delivery of IT services in line with business } \\
\text { requirements }\end{array}$ & $\mathbf{P}$ & $\mathbf{P}$ & $\mathbf{S}$ & $\mathbf{S}$ & & $\mathbf{P}$ & $\mathbf{S}$ & $\mathbf{P}$ & $\mathbf{S}$ & & $\mathbf{P}$ & $\mathbf{S}$ & $\mathbf{S}$ & & & $\mathbf{S}$ & $\mathbf{S}$ \\
\hline$\stackrel{\mathscr{C}}{0}$ & 8 & $\begin{array}{l}\text { Adequate use of applications, information and } \\
\text { technology solutions }\end{array}$ & $\mathbf{S}$ & S & $\mathbf{S}$ & & & S & $\mathbf{S}$ & & $\mathbf{S}$ & $\mathbf{S}$ & $\mathbf{P}$ & $S$ & & $\mathbf{P}$ & & $\mathbf{S}$ & S \\
\hline \multirow{7}{*}{ 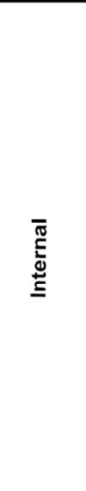 } & 9 & IT agility & $S$ & $P$ & S & & & $S$ & & $P$ & & & $P$ & & $S$ & $S$ & & $\mathrm{~S}$ & $P$ \\
\hline & 10 & $\begin{array}{l}\text { Security of information, processing infrastructure } \\
\text { and applications }\end{array}$ & & & $\mathbf{P}$ & $\mathbf{P}$ & & & $\mathbf{P}$ & & & & & & & & $\mathbf{P}$ & & \\
\hline & 11 & $\begin{array}{l}\text { Optimasation of IT assets, resources and } \\
\text { capabilities }\end{array}$ & $\mathbf{P}$ & $\mathbf{S}$ & & & & & & $\mathbf{S}$ & & $\mathbf{P}$ & $\mathbf{S}$ & $\mathbf{P}$ & $\mathbf{S}$ & $\mathbf{S}$ & & & $\mathbf{S}$ \\
\hline & 12 & $\begin{array}{l}\text { Enablement and support of business procesess } \\
\text { by integrating applications and technology into } \\
\text { business processes }\end{array}$ & $\mathbf{S}$ & $\mathbf{P}$ & $\mathbf{S}$ & & & $\mathbf{S}$ & & $\mathbf{S}$ & & $\mathbf{S}$ & $\mathbf{P}$ & $\mathbf{S}$ & $\mathbf{S}$ & $\mathbf{S}$ & & & $\mathbf{S}$ \\
\hline & 13 & $\begin{array}{l}\text { Delivery of programmees delivering benefits, on } \\
\text { time, on budget, and meeting requirements and } \\
\text { quality standarts }\end{array}$ & & S & $\mathbf{S}$ & & & $\mathbf{S}$ & & & & $\mathbf{S}$ & & $\mathbf{S}$ & $\mathbf{P}$ & & & & \\
\hline & 14 & $\begin{array}{l}\text { Availability of reliable and useful information for } \\
\text { decision making }\end{array}$ & S & s & $\mathbf{S}$ & S & & & $\mathbf{P}$ & & $\mathbf{P}$ & & $\mathbf{S}$ & & & & & & \\
\hline & 15 & IT compliance with internal policies & & & $S$ & s & & & & & & & & & & & $P$ & & \\
\hline \multirow{2}{*}{ 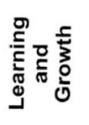 } & 16 & $\begin{array}{l}\text { Competent and motivated business } \\
\text { and IT personel }\end{array}$ & $\mathbf{S}$ & $\mathbf{S}$ & $\mathbf{P}$ & & & $\mathbf{S}$ & & $\mathbf{S}$ & & & & & & $\mathbf{P}$ & & $\mathbf{P}$ & $\mathbf{S}$ \\
\hline & 17 & $\begin{array}{l}\text { Knowledge, expertise, and initatives for business } \\
\text { innovation }\end{array}$ & $\mathbf{S}$ & $\mathbf{P}$ & & & & S & & $\mathbf{P}$ & S & & $\mathbf{S}$ & & S & & & $\mathbf{S}$ & $\mathbf{P}$ \\
\hline
\end{tabular}

Gambar 3. Hasil Pemetaan Tujuan Organisasi untuk Sasaran Terkait TI 
3) Pemetaan SI/TI yang berkaitan dengan target sasaran ke Proses.

Berlandaskan hasil pada gambar 3, yang telah dijalankan, terdapat 4 (empat) domain yang mempunyai skala $\mathrm{P}$ (primer) yang dimana merupakan target sasaran yang berkaitan dengan SI/TI dan merupakan dukungan yang utama dalam tujuan organisasi. Dari keempat domain yang didapatkan tersebut antara lain EDM01 (Ensure Governance Framework setting and maintenance), EDM02 (Ensure Benefits Delivery), EDM03 (Ensure Risk Optimisation), dan EDM05 (Ensure Stakeholder Transparency) seperti yang digambarkan pada Gambar 4. Untuk mendapatkan kuesioner yang mengarah pada COBIT 5 yakni PAM (Process Assesment Model) dari ISACA [5].

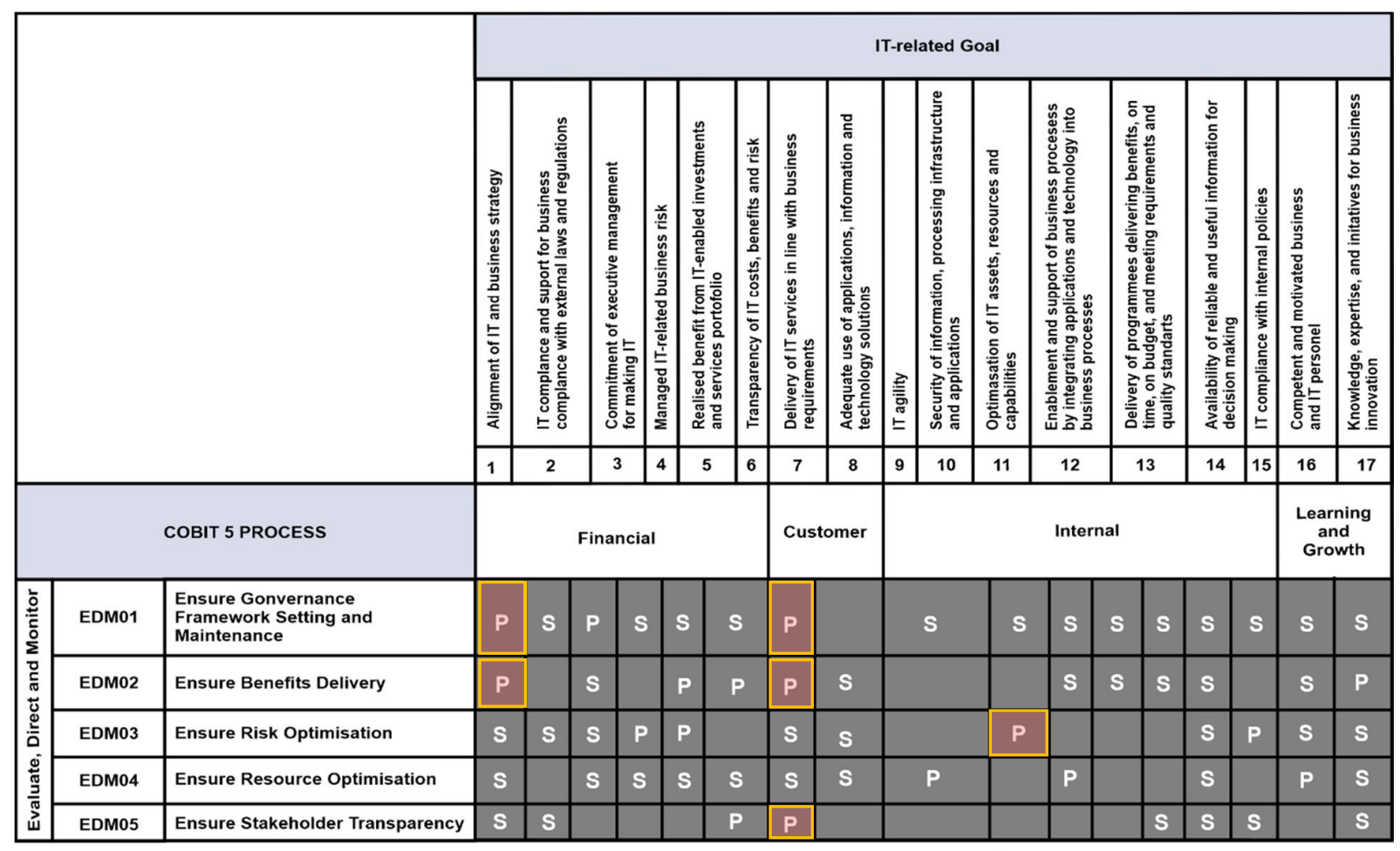

Gambar 4. Hasil Pemetaan TI Relasi Sasaran ke Proses

4) Tahapan Pengukuran Tingkatan Kapabilitas. Pada tahapan ini, dengan melakukan penilaian terhadap domain yang akan digunakan, dimana pada tahap ini, domain yang digunakan tersebut di uji sesusai dengan tahapan, agar proses tersebut memenuhi syarat yang digunakan pada setiap tahapan. Pengujian dilakukan dari tahap 1 sampai 5. Agar syarat penilaian terpenuhi terdapat beberapa aspek pada masing-masing tingkatannya, pada setiap proses akan didapatkan kategori L yaitu Largely achieved dimana jika nilai ini memperoleh angka 50-80\% namun jika nilai yang diperoleh mencapai $85-100 \%$, tingkatan yang dihasilkan adalah $\mathrm{F}$ yaitu Full achieved [6].

Hasil dari penilaian tingkatan kapabilitas tersebut digambarkan pada grafik penilaian tingkatan kapabilitas di Gambar 5 [10].

Pada Gambar 5 tersebut merupakan hasil dari penilaian tingkatan kapabilitas yang berkaitan dengan domain EDM, yaitu:

Teguh, et., al [Evaluasi Pemanfaatan Teknologi Informasi Di Desa Tarinsing Menggunakan Metode Cobit 5.0] 
1) Tingkat 1, mendapat 2 domain yaitu domain EDM 02 dan EDM 03

2) Tingkat 2, mendapat 1 domain yaitu domain EDM 01

3) Tingkat 3, mendapat 1 domain yaitu domain EDM 05

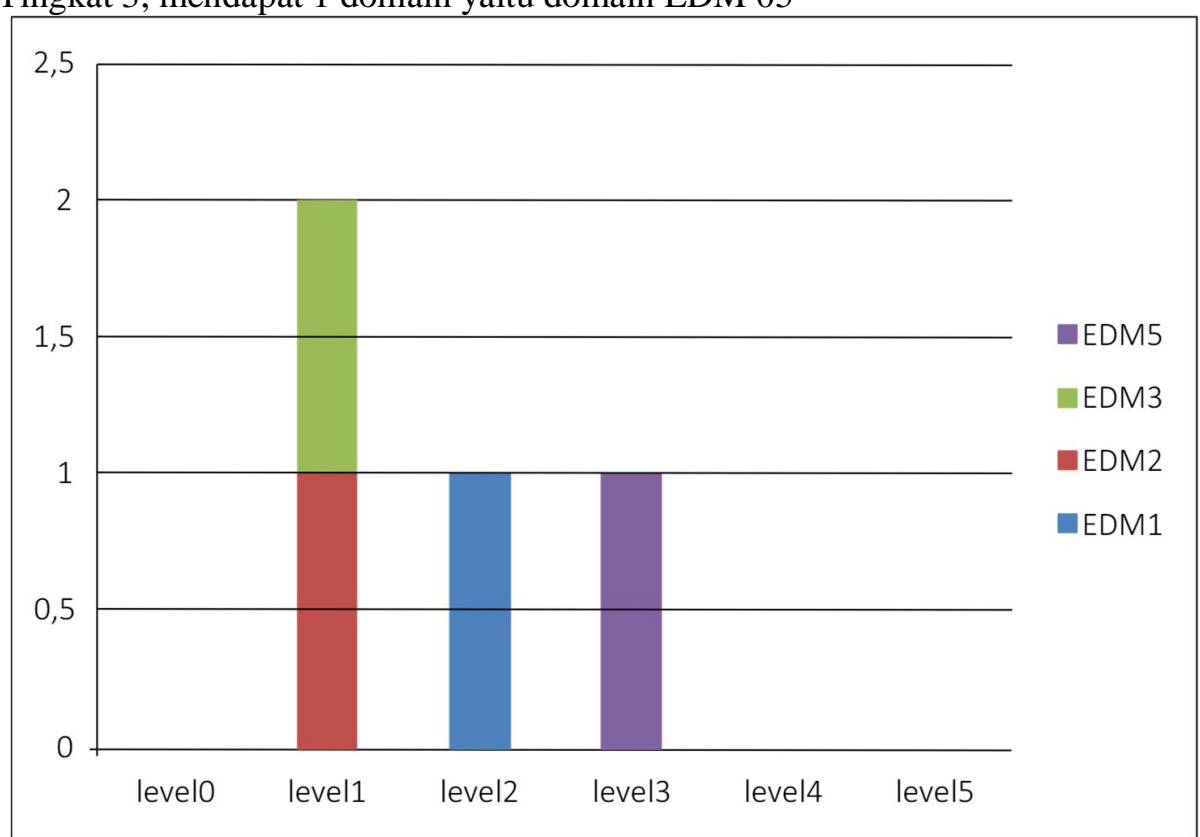

Gambar 5. Grafik Penilaian Tingkatan Kapabilitas

Dalam grafik ini, yang digambarkan pada Gambar 5 diatas, selanjutnya didapatkan diagram jaring laba-laba, diagram jaring laba-laba ini menunjukan nilai dari tingkatan kapabilitas, sasaran tingkatan kapabilitas ini menghasilkan GAP dari masing-masing target EDM yang dinilai, sesuai dengan yang ditunjukan di Gambar 6 dibawah.

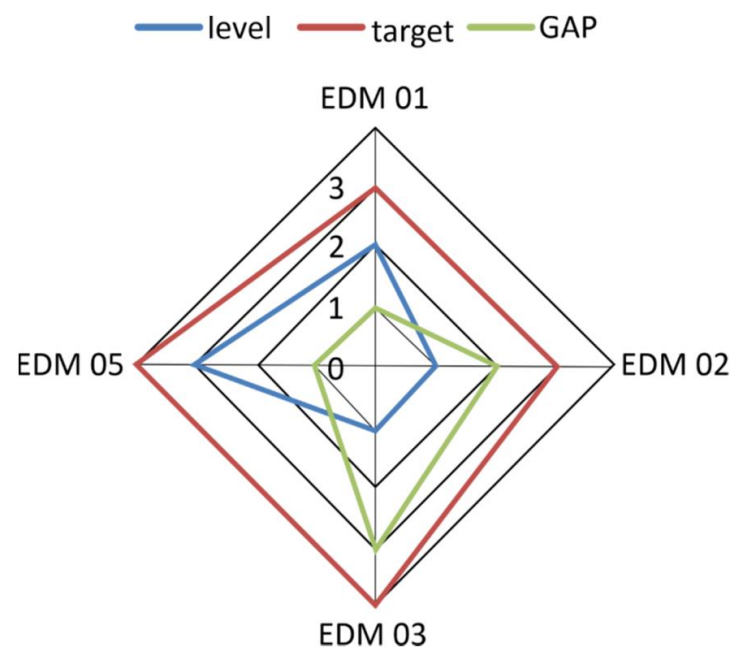

Gambar 6. Diagram Jaring Laba-laba Analisis Kesenjangan 
Dari hasil penilaian pada 4 target domain yang didapatkan, dapat dibuat sebagai referensi sebagai alat yang dapat digunakan dalam analisis GAP yang diawali pada target yang diharapkan. Hasil ini dapat dilihat pada tabel $1[10]$ :

Tabel 1. Hasil Analisis Kesenjangan

\begin{tabular}{cclccc}
\hline No & $\begin{array}{c}\text { IT } \\
\text { Process }\end{array}$ & \multicolumn{1}{c}{ Keterangan } & Tingkat & Target & GAP \\
\hline 1 & EDM 01 & $\begin{array}{l}\text { Kerangka kerja tata kelola telah } \\
\text { diatur dan mengadakan perawatan } \\
\text { secara berkala }\end{array}$ & 2 & 3 & 1 \\
2 & EDM 02 & $\begin{array}{l}\text { Menentukan keuntungan dalam setiap } \\
\text { proses yang dijalankan }\end{array}$ & 1 & 4 & 2 \\
3 & EDM 05 & $\begin{array}{l}\text { Memastikan Optimasi Resiko } \\
\text { EDM }\end{array}$ & 1 & 3 & 3 \\
\hline
\end{tabular}

Berdasarkan hasil analisis kesenjangan yang ditunjukan pada Tabel 1. Berikutnya dilakukan perhitungan rata-rata dari setiap tingkatan kapabilitas. Dalam perhitungan ini peneliti menggunakan rumus yang mengarah kedalam penelitian. Rumus dari perhitungan tersebut dapat dilihat pada rumus 1 .

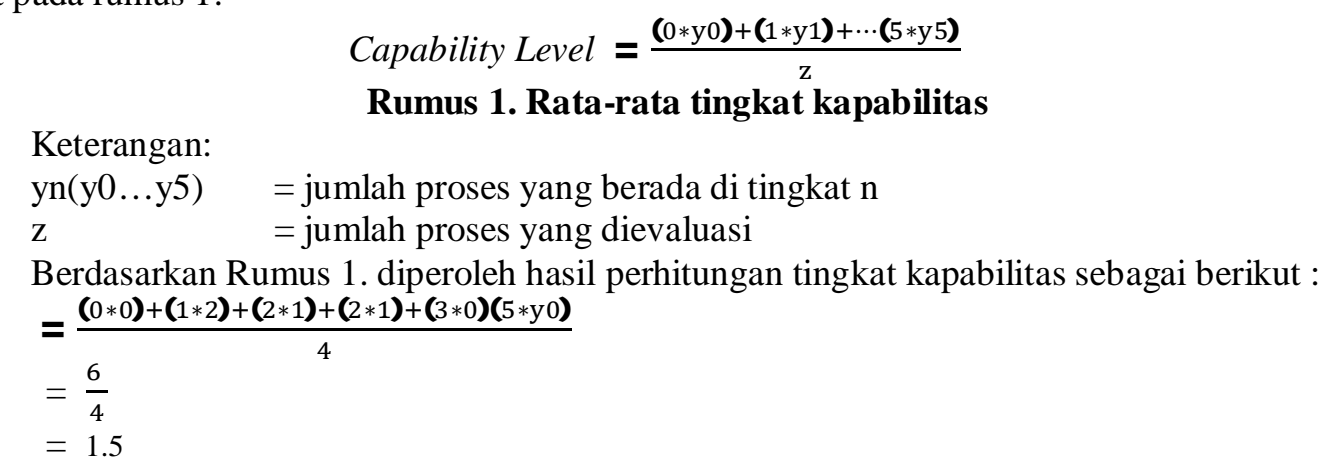

\section{KESIMPULAN}

Dari hasil penilaian dan perhitungan dari rata-rata tingkatan kapabilitas yang diperoleh dari masing-masing domain EDM01 (Ensure Governance Framework setting and maintenance), EDM02 (Ensure Benefits Delivery), EDM03 (Ensure Risk Optimisation), dan EDM05 (Ensure Stakeholder Transparency) maka dapat disimpulkan hasil yang diperoleh dari tingkatan kapabilitas dari Desa Transing dalam pengadaan SI/TI pada Kantor Pemerintahan Desa Tarinsing yaitu mendapat pada tingkat 1 (sudah dijalankan) dan mendapatkan nilai 1,5 . Kondisi tersebut memperlihatkan jika pengadaan TI pada desa Tarinsing sudah berjalan sesuai dengan tujuannya, akan tetapi tidak terdapat suatu tujuan yang dapat mengolah suatu keuntungan dari setiap kegiatan yang dijalankan serta penanganan risiko yang ditetapkan, agar sesuai dengan keluaran yang diharapkan.

Agar bisa mendapatkan kegunaan SI/TI secara maksimal yang tepat dan selaras dengan tujuan organisasi, oleh karena itu desa Tarinsing harus melakukan pembenahan dan merapikan tata kelola SI/TI baik secara menyeluruh dan juga berkelanjutan. Dari proses tersebut dimulai dengan 
target pada tingkat 1 secara bertahap hingga mencapai tingkat 3 , yakni dilakukan dengan menyelaraskan proses keseluruhan keluaran yang masih belum bisa didapatkan pada tingkat 1, langkah berikutnya fokus pada tingkat 2 serta dilakukan perubahan yang sesuai secara bertahap agar dapat mencapai ke tingkat yang ke 3 .

\section{SARAN}

Diharapkan bisa meningkatkan penggunaan TI pada Kantor Pemerintahan Desa Tarinsing sesuai dengan hasil penelitian, yaitu:

1) Kantor Pemerintahan Desa Tarinsing lebih baik mengadakan dan menetapkan sebuah SOP (Standard Operasional Prosedur) untuk bisa memperoleh syarat yang terdapat di tingkat 3 dan selaras dengan tujuan yang diharapkan.

2) Sebaiknya diprioritaskan keperluan Kantor Pemerintahan Desa Transing dapat dipilih untuk yang selaras dengan tujuan dan target yang terdapat pada organisasi serta dapat diawali dengan target yang memiliki pengaruh besar bagi organisasi tersebut, serta dapat melakukan evaluasi secara bertahap dari keseluruhan setiap domain yang sesuai dengan framework COBIT 5.

\section{UCAPAN TERIMAKASIH}

Penulis mengucapkan terimasih kepada dosen pembimbing yakni, pak Kristoko Dwi Hartomo yang telah memberikan dukungan dalam penyelesaian pembuatan jurnal ini.

\section{DAFTAR PUSTAKA}

[1] U.-U. R. I. N. 23 and 2014. Tentang Pemerintahan Daerah. Indonesia, 2014, "No Title," [Online]. Available: https://pih.kemlu.go.id/files/UU0232014.pdf.

[2] I. E. Kaban, "Tata Kelola Teknologi Informasi," pp. 1-5, [Online]. Available: https://journal.binus.ac.id/index.php/commit/article/view/505/483.

[3] Rolling Meadows, IT Governance Institute, Board Briefing on IT Governance. .

[4] J. W. Ross, "IT Governance," [Online]. Available: https://www.academia.edu/23204964/IT_Governance_How_Top_Performers_Manage_IT_ Decision_Rights_for_Superior_Results?auto=download.

[5] T. Asterinadewi, Y. Handoko, M. S. Informasi, and U. K. Indonesia, "Asesmen Kapabilitas Mengunakan Kerangka Kerja Cobit 5 Process Assessment Model Dalam,” No. ii, pp. 61-70, [Online]. Available: https://ojs.unikom.ac.id/index.php/jtk3ti/article/download/463/323.

[6] ISACA, “COBIT 5: Enabling Processes," [Online]. Available: https://repository.dinus.ac.id/docs/ajar/Pertemuan_6_Enabling_Process_COBIT.pdf.

[7] T. S. Sukamto, "COBIT 5 sebagai IT Governance Framework The COBIT 5 Framework,"

Teguh, et., al [Evaluasi Pemanfaatan Teknologi Informasi Di Desa Tarinsing Menggunakan Metode Cobit 5.0] 
[Online].

Available: https://repository.dinus.ac.id/docs/ajar/Pertemuan_89_COBIT_5_Sebagai_ITG_Framework. pdf.

[8] A. Hakim et al. 2014, "Jurnal Sistem Informasi (Journal of Information Systems). 2 / 10 ( 2014 ), 108-117 DOI: http://dx.doi.org/10.21609/jsi.v10i2.393,” Vol. 10, pp. 108-117, [Online]. Available: http://dx.doi.org/10.21609/jsi.v10i2.393.

[9] H. T. Sihotang, H. Lumbantoruan, T. Informatika, M. Informatika, S. Utara, and I. G. Kompetensi, "Evaluasi Tingkat Kematangan Tata Kelola Teknologi Informasi dan Komunikasi (Tik) Dengan Framework Cobit 5 . 0 pada STMIK Pelita Nusantara Medan," Vol. 2, No. 2, pp. 58-66, 2018, [Online]. Available: http://www.ejurnal.pelitanusantara.ac.id/index.php/mantik/article/view/414.

[10] R. P. Aji, "Penilaian Tata Kelola Teknologi Informasi pada Dinas Kesehatan Kabupaten Banyumas Mengacu pada Kerangka Kerja Cobit 5," Vol. 12, No. 2, pp. 13-24, [Online]. Available:

http://ejournal.amikompurwokerto.ac.id/index.php/probisnis/article/download/794/508. 